\title{
Tools for measuring gender equality and women's empowerment (GEWE) indicators in humanitarian settings
}

Céline M. Goulart (D, Amber Purewal, Humaira Nakhuda, Anita Ampadu, Amanda Giancola, Jean-Luc Kortenaar and Diego G. Bassani

\begin{abstract}
Background: Effective measurement of Gender Equality and Women's Empowerment (GEWE) is challenging in low and middle-income countries (LMICs), and even more so in humanitarian settings. Conflict, natural disasters, and epidemics may increase gender inequities, but also present an opportunity to address them. This scoping review describes and identifies gaps in the measurement tools, methods, and indicators used to measure GEWE in humanitarian settings, and presents a dashboard that can be used by researchers, organizations and governments to identify GEWE measurement tools.
\end{abstract}

Methods: Scientific articles published between January 2004 and November 2019 were identified using Embase, Medline, PsycInfo, CINAHL, Scopus, and PAIS index. Relevant non peer-reviewed literature was downloaded from the websites of humanitarian organizations. Publications on women and/or girls impacted by a humanitarian crisis in a LMIC, within 5 years of data collection, were included. Publications were double-screened in the title/abstract and full-text stages. We used a machine learning software during the title/abstract screening to increase the efficiency of the process. Measurement tools, sampling and data collection methods, gap areas (geographical, topical and contextual), and indicators were catalogued for easy access in an interactive Tableau dashboard.

Results: Our search yielded 27,197 publications and 2396 non peer-reviewed literature reports. One hundred and seventy publications were included in the final review. Extracted indicators were categorized into seven domains: economic, health, human development, leadership, psychological, security and justice, and sociocultural. The vast majority of studies were observational, and over $70 \%$ utilized a cross-sectional study design. Thirty-eight toolkits and questionnaires were identified in this review, of which 19 (50\%) were designed specifically for humanitarian settings. Sociocultural was the largest domain in number of studies and indicators in this review, with gender-based violence indicators reported in $66 \%$ of studies. Indicators of economic, human development and leadership were uncommon in the peer-reviewed literature.

Discussion: While there has been some effort to measure GEWE in conflict-affected and other humanitarian settings, measurement has largely focused on violence and security issues. A more comprehensive framework for measuring GEWE in these settings is needed; objective measurement of women's empowerment and gender equality should be prioritized by organizations providing humanitarian aid.

Keywords: Girls and women, Humanitarian, Measurement methods, Gender equality, Women's empowerment

\footnotetext{
* Correspondence: celine.goulart@mail.utoronto.ca

The Hospital for Sick Children, 686 Bay St, Toronto, ON M5G 0A4, Canada
}

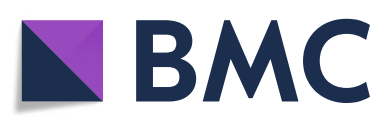

(c) The Author(s). 2021 Open Access This article is licensed under a Creative Commons Attribution 4.0 International License, which permits use, sharing, adaptation, distribution and reproduction in any medium or format, as long as you give appropriate credit to the original author(s) and the source, provide a link to the Creative Commons licence, and indicate if changes were made. The images or other third party material in this article are included in the article's Creative Commons licence, unless indicated otherwise in a credit line to the material. If material is not included in the article's Creative Commons licence and your intended use is not permitted by statutory regulation or exceeds the permitted use, you will need to obtain permission directly from the copyright holder. To view a copy of this licence, visit http://creativecommons.org/licenses/by/4.0/. The Creative Commons Public Domain Dedication waiver (http://creativecommons.org/publicdomain/zero/1.0/) applies to the data made available in this article, unless otherwise stated in a credit line to the data. 


\section{Background}

Achieving gender equality and women's empowerment are key components of improving the wellbeing of all people [1]. Goal five of the Sustainable Development Goals (SDGs) focuses on achieving gender equality and empowering all women and girls (Goal 5: Achieve gender equality and empower all women and girls). Key targets of this goal include ending discrimination against women and girls, eliminating violence/harmful practices that target women and girls, recognizing the unpaid care/domestic labor performed by women, ensuring equal opportunities for women's participation and leadership, and securing universal access to sexual and reproductive health and rights (SRHR) for all women and girls [1].

It is estimated that more than 80 million people were forcibly displaced worldwide due to conflict, persecution, and other human rights violations at mid-2020 [2]. These crises disproportionately affect the wellbeing of women and children as a result of pre-existing biological and sociocultural factors [3, 4]. Women may have less access to finances, goods and training to protect themselves during crises [3]. They also bear the majority of the caregiving responsibilities in many of these settings [4]. Women and girls represent just over $50 \%$ of the global refugee and IDP populations, yet only $4 \%$ of projects in the UN inter-agency appeals targeted women and girls in 2014 [5]. Furthermore, these crises can exacerbate gender inequalities and risks for women and girls [6], making it important to employ gender-appropriate tools when collecting data about women and girls in humanitarian settings. Gender appropriate tools are crucial when seeking to understand gender equality, as they provide sex-disaggregated indicators, along with indicators that are specific to the sociocultural, health and safety needs of women and girls [7].

\section{Summary of existing literature and framework used}

Empowerment is defined as the process of change in one's ability to exercise choice [8]. Previous research has focused on the impact of gender equality and women's empowerment (GEWE) on maternal health and family planning (FP), children's health outcomes, and SRHR. Women's empowerment is a social determinant of maternal and child health [9]. It is positively associated with women's contraceptive use in low- and middle-income countries (LMICs) [10] and reductions in under-five mortality [11]. The measurement of GEWE in humanitarian settings has often been approached from a biomedical lens, focusing on SRHR outcomes specifically [12]. However, domains of GEWE, outside of those pertaining to gender-based violence (GBV), have not been routinely or consistently measured in these settings.
Various conceptual frameworks exist for measuring women's empowerment. Kabeer established three dimensions of empowerment: agency, resources, and achievements [8]. Resources enhance a woman's ability to exercise choice, while agency refers to her ability to act on those choices. Another conceptual model of empowerment developed by van Eerdewijk et al. also includes agency and resources, but adds institutional structures, to the dimensions [13]. In this model, agency includes decision-making, collective agency, and leadership; resources pertain to women and girls' bodily integrity, critical consciousness, and assets; and institutional structures refer to the formal laws/policies and norms that impact the ability of women and girls to assert control over resources [13]. Either of the frameworks above may be used to organize measures of GEWE in humanitarian settings.

This scoping review categorizes GEWE indicators into the following domains: economic, health, human development, leadership, psychological, security and justice, and sociocultural. The economic domain captures indicators on employment, financial decision-making, and income generation. The health domain includes indicators on bodily autonomy, health perceptions, and access to services, whereas the human development domain captures access to basic needs, education, and vocational training. Indicators that measure a change/effect in women's empowerment resulting from an intervention are also categorized under human development. The leadership domain includes indicators on leadership qualities and community participation. The psychological domain captures indicators on women's selfesteem and social support. The security and justice domain captures laws/policies that affect women, as well as their sense of safety and security in their respective communities. Lastly, the sociocultural domain captures the prevalence of GBV, as well as the cultural norms and attitudes relating to women's autonomy.

Reliable measurement of gender-relevant indicators in humanitarian settings is difficult, as data is usually unavailable and primary data collection is costly and timeconsuming [14]. In order to streamline data collection and other measurement processes in such settings, simpler approaches to valid and reliable gender-relevant indicators need to be identified.

\section{Objective}

A scoping review is a synthesis of current research to map the literature available on a topic of interest, and is therefore useful way to identify the tools and strategies used to measure GEWE in humanitarian settings [15]. It is also a useful way to identify any limitations and gaps in the use of measurement tools, indicators, and data sources [16]. Hence, a scoping review was conducted to 
systematically map and assess existing indicators, data sources, and methodologies, as well as to identify knowledge gaps in GEWE in humanitarian settings. Results from this review were then used to create an interactive Tableau dashboard.

\section{Methods}

This scoping review was conducted in accordance with the Preferred Reporting Items for Systematic Reviews and Meta-Analyses (PRISMA) statement [17].

\section{Definitions and inclusion criteria}

We used terms associated with our seven domains of gender equality and women's empowerment to build our search strategy. The term 'women' rather than 'females' was used, to ensure that persons who identify as women, but were not assigned 'female' at birth, were included in this review. We defined a humanitarian crisis as "a serious disruption of the functioning of a community or a society causing widespread human, material, economic or environmental losses which exceed the ability of the affected community or society to cope using its own resources, necessitating a request to national or international level for external assistance. The disaster situation may either be manmade (e.g. armed conflict) or a natural phenomenon (e.g. drought)" [18]. We further stipulated that the humanitarian event had to result in over 1000 human casualties and had to be distinct from latent civil unrest/conflict, or long-standing epidemics, such as HIV. See Additional file 1 for the full search strategy.

For a publication to meet the inclusion criteria, it had to:

- Include women and/or girls that had been impacted by a humanitarian crisis in a low and middle-income country (LMIC). Data must have been collected either during the time of the humanitarian event or no more than 5 years post-event. This included populations who had fled a country with ongoing conflict living in unaffected LMICs. Refugee populations living in high-income countries were excluded.

- Be an interventional or observational study on a GEWE-related topic.

- Be published on or after January 1st, 2004 to November 27th, 2019. Publications before the year 2004 were excluded on the basis of relevance, and for feasibility given the large scope of the review.

- Be in the English language or have an English translation available online.

- Measure quantitative GEWE outcomes.

Qualitative studies or those reporting crude numbers without denominators, and studies without any measurement methods were excluded. See Additional file 2 for detailed inclusion and exclusion criteria.

\section{Search}

On November 27th, 2019, we ran our search strategy on the following databases: Embase, Medline, PsycInfo, CINAHL, Scopus, and PAIS index.

The following websites and databases were searched for relevant non peer-reviewed literature: United Nations Population Fund (UNFPA), United Nations High Commission for Refugees (UNHCR), Oxfam, Care International, UN Women, the World Health Organization (WHO), the United Nations Development Programme (UNDP), International Rescue Committee (IRC), International Committee of the Red Cross (ICRC), World Vision, Médecins Sans Frontières (MSF) Field Research, Active Learning Network for Accountability and Performance (ALNAP), Save the Children International (SCI), Sexual Violence Research Initiatives (SVRI), InterAgency Working Group on Reproductive Health in Crises (IAWG), Women's Refugee Commission, $\mathrm{Hu}$ manitarian Response, Relief Web, The Gender and Development Network, International Alert, Women Deliver, ProMundo, International Center for Research on Women (ICRW) and Plan International. The first 200 citations from each source were screened. This non peer-reviewed literature search was conducted concurrently with our SRHR scoping review [12], such that SRHR non peer-reviewed literature articles identified as relevant to GEWE in the screening phase could be duplicated in the GEWE non peer-reviewed literature screening process.

\section{Screening process}

In order to accelerate the title and abstract screening phase of the scoping review, we developed a machine learning software to rank the relevance of the abstracts from our database search. Details of our machine learning tool can be found in Additional file 3. Machine learning software was used as it increased the efficiency of the screening process [19].

Additional resources were used to retrieve GEWE publications. First, reference lists from relevant systematic reviews retrieved from our database search were screened. Second, GEWE publications identified in the SRHR search results were transferred to this review. These two procedures contributed an additional 48 publications to the study count.

After the title and abstract screening process, the remaining articles were full text screened by two reviewers for eligibility and assigned an exclusion reason if they did not meet the study criteria. 


\section{Data extraction and analysis}

Included studies were extracted in duplicate into a Microsoft Excel spreadsheet. A narrative synthesis [20] was conducted to group the indicators thematically, into seven different domains of equality/empowerment. We sorted indicators into types and subtypes for each domain of GEWE. Extracted and organized data were then cleaned and frequencies were tabulated using STATA: Software for Statistics and Data Science [21]. Demographics, measurement methods and tools, and indicators were counted once per study. These counts were interpreted using the narrative synthesis method, to describe the measurement methods and gaps. The toolkits and surveys employed within the included studies were then organized in a table, found in Additional file 4.

A dashboard was created using Tableau to display the measurement methods, tools, indicators and gaps identified in this study. This dashboard is accessible online, along with the results from our SRHR review [22]. See Additional file 5 to access a link to this dashboard.

\section{Results}

Our search yielded 27,197 publications and 2396 non peer-reviewed literature reports. After removing duplicates, conducting the title/abstract and full-text screenings for our inclusion criteria, 170 publications were included in the final review (Fig. 1). See Additional file 6 for the complete list of studies.

\section{Study characteristics}

Study characteristics of included papers are listed in Fig. 2. One hundred and forty-eight publications collected data on conflict-affected populations, accounting for $87 \%$ of studies in the review. Geographic locations are illustrated in Fig. 3. Forty-five countries were covered by the studies included in this review, with the largest

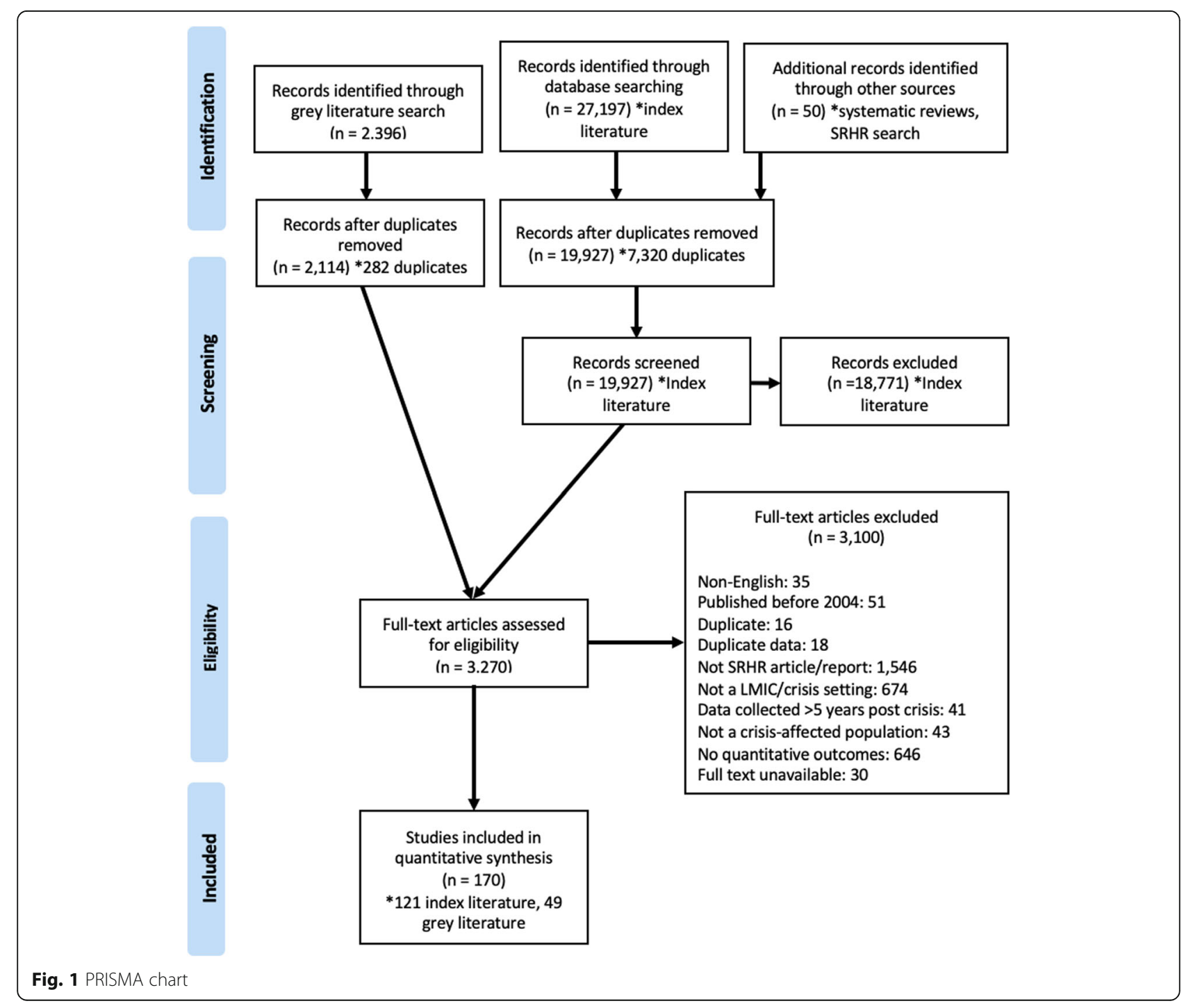




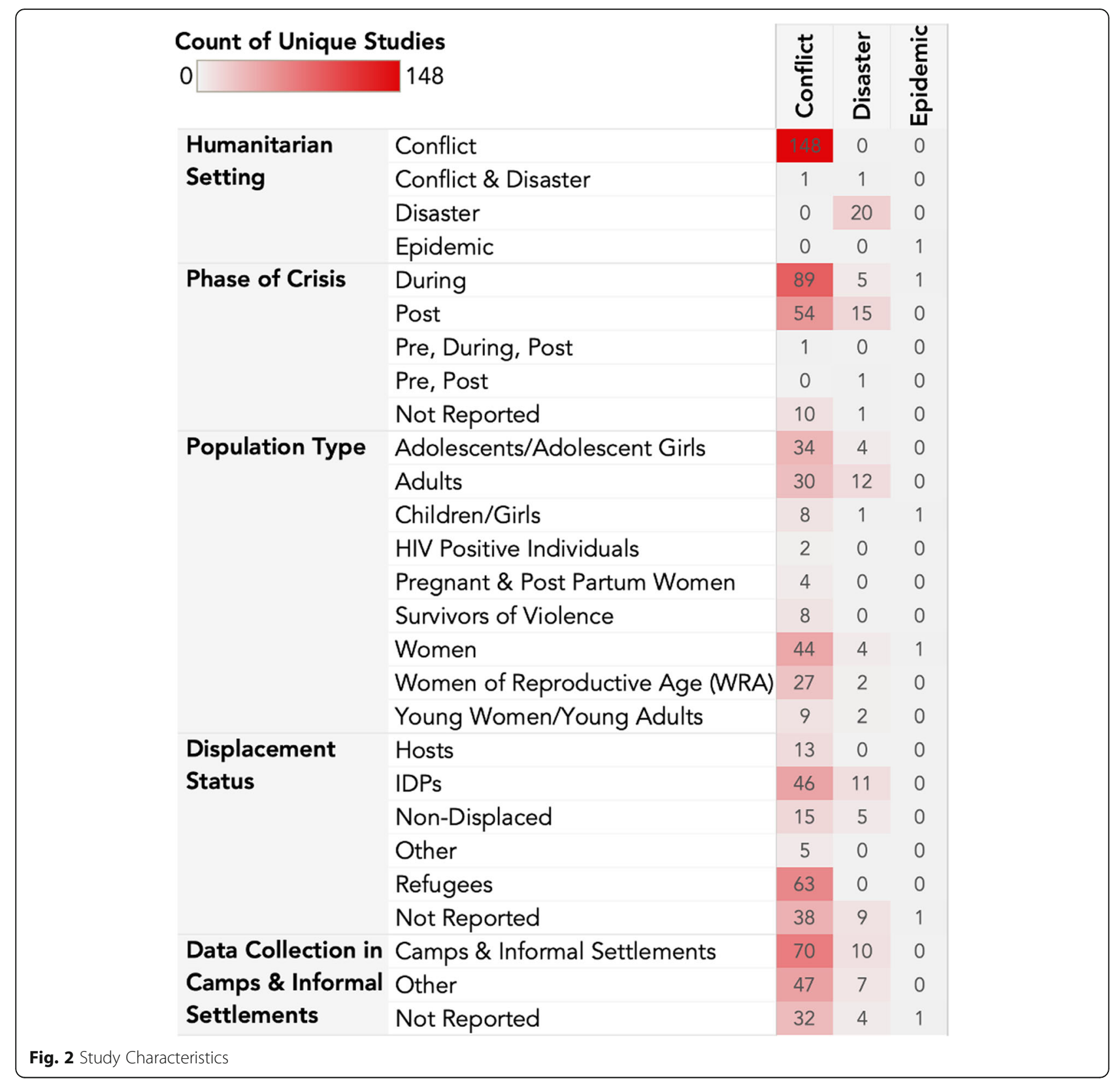

number of studies conducted in the Democratic Republic of the Congo (DRC), Uganda, Jordan, and Ethiopia. Twenty studies (12\%) collected data in disaster and postdisaster settings, and only one $(0.6 \%)$ was in an epidemic setting. The most common disaster setting was Haiti. Of the disaster literature, 8 studies were about earthquakes, 4 about drought, 3 about typhoons, 3 about floods. Additionally, one study was about a tsunami while another was about volcanic disaster. See Additional file 7 for more details. Of the 63 studies that collected data with refugee populations, the majority focused on refugees from Syria, DRC, South Sudan, Sudan and Myanmar (combined total of $n=21(33 \%)$ ).
Forty-six (31\%) conflict studies and 11 (55\%) disaster studies were conducted among populations of internally displaced persons (IDP). Nearly $50 \%$ of studies were with populations residing in camps and informal settlements. Women, adolescents, adults, and women of reproductive age (WRA) made up the majority of the study populations in this review. Children and girls appeared in only ten studies (6\%) (Fig. 4).

\section{Measurement methods used}

Common measurement methods identified by this review are summarized in Fig. 5. Of 170 studies included in this review, 148 (87.1\%) of the studies were 


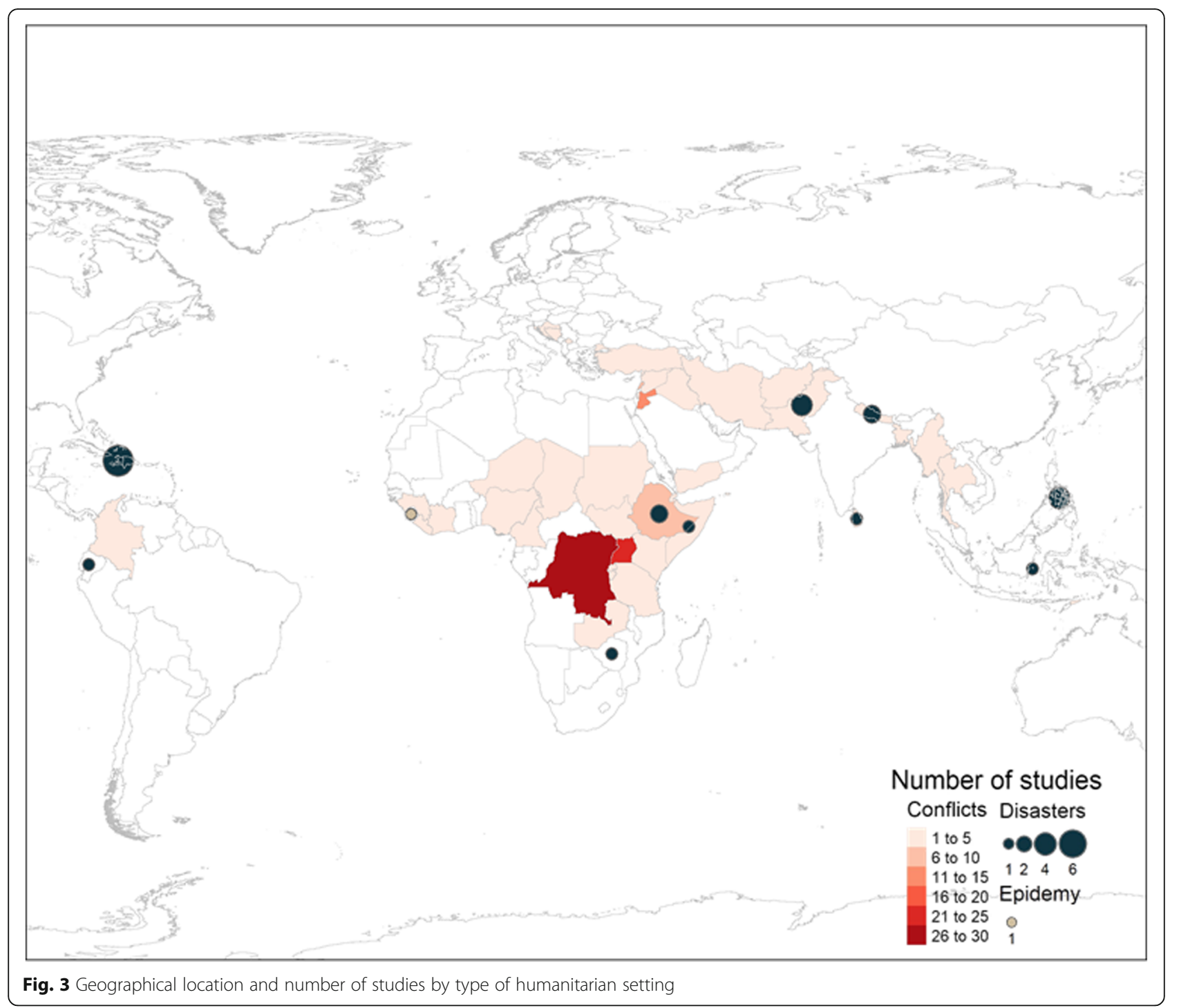

observational, and only $22(12.9 \%)$ were interventional. Thirteen (59\%) of the interventional studies were randomized controlled trials (RCTs). Over $80 \%(n=121)$ of the observational studies were cross-sectional surveys. Thirty-three (19.4\%) studies were conducted at the facility-level, while $134(78.8 \%)$ were conducted at the population level. Of all the indicators measured in this study, 36\% were sex-disaggregated.

Eighty-three (49\%) studies used a probability sampling method. Cluster sampling and random sampling were the most commonly reported probability methods. Sixtythree (37\%) studies utilized a non-probability method, with $29(46 \%)$ of these studies using convenience sampling. Two (1\%) studies used a combination of probability and non-probability methods, while 22 (13\%) studies did not report the sampling method used (Fig. 5). Interviewer-administered questionnaires, self-administered questionnaires, and audio computer-assisted self-interviews
(ACASI) were the most commonly used measurement methods ( $n=146$ (86\%), $n=8$ (5\%), and $n=9$ (5\%), respectively).

Thirty-eight toolkits were identified in this review, of which 22 (58\%) were sex-disaggregated and 19 (50\%) were designed specifically for humanitarian settings. The three most commonly used toolkits were the WHO Multi-Country Study on Women's Health and Domestic Violence Against Women $(n=16(9 \%))$, Demographic and Health Survey (DHS) $(n=12(7 \%))$ and the Centre for Disease Control (CDC) Reproductive Health Assessment Toolkit for Conflict Affected Women $(n=8(5 \%))$. Refer to Additional file 4 for a full list of toolkits.

\section{Domains of equality/empowerment}

The sociocultural domain was included in the largest number of studies in this review, appearing in 137 (81\%) of 170 studies. The GBV indicator type accounted for 


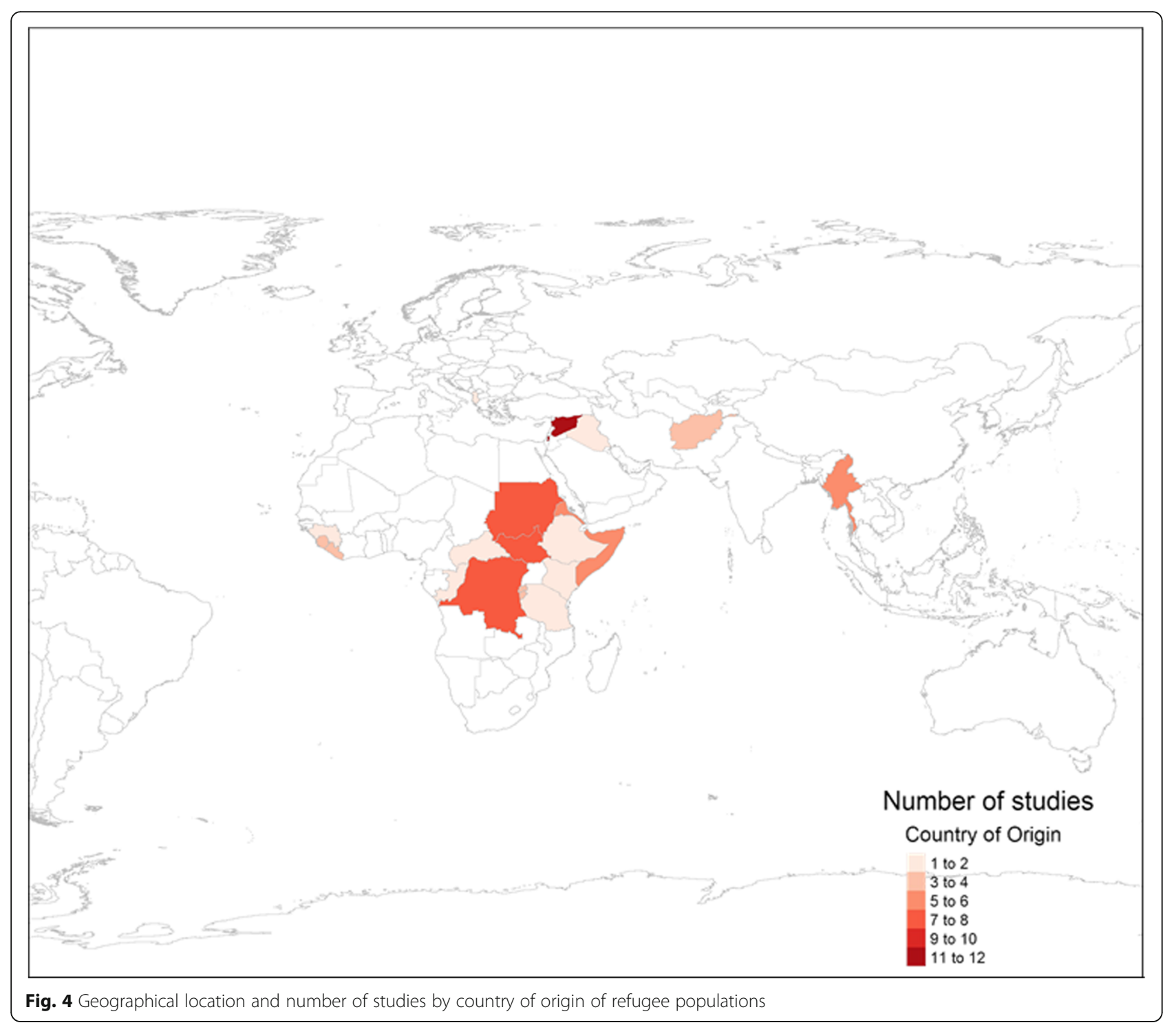

97\% of this domain's indicators $(n=133)$. The security and justice, economic, and health domains were found in 72 (42\%), 73 (43\%), and 70 (41\%) studies, respectively. Fifty (29\%) studies included human development, and 25 (15\%) included psychological indicators. Leadership was the least frequently identified domain, appearing in only 15 (9\%) studies. Figure 6 shows the organization of indicators by domain.

\section{Gaps in measurement}

Figure 7 illustrates the various gaps identified by our scoping review. Indicator types/subtypes that were present in ten or more of the 170 papers included in this scoping review are considered common across studies. Indicator types/subtypes used in five or more countries are considered common across countries. Indicator types/ subtypes that were present in five or more studies in the peer-reviewed literature are considered common in the peer-reviewed literature. Indicator types/subtypes that are measured among men and women separately in at least $50 \%$ of the studies, are considered sex-disaggregated. Indicator types/subtypes that are found in three or more toolkits are considered common across the toolkits. Finally, an indicator type/subtype is measured in detail when it is measured by the same indicator in three or more studies, or three or more different indicators within one study. See Additional file 8 for a full list of indicator types and subtypes.

\section{Economic}

We found that the economic domain was reported in $78 \%$ of the non-peer-reviewed literature but was only found in $29 \%$ of studies in the peer-reviewed literature. Although indicators of economic control were captured 


\begin{tabular}{|c|c|c|c|c|}
\hline \multicolumn{2}{|c|}{ Count of Unique Studies } & \multirow[b]{2}{*}{ 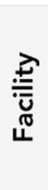 } & \multirow[b]{2}{*}{$\begin{array}{l}\frac{0}{0} \\
\frac{0}{0} \\
\frac{0}{3} \\
\frac{0}{0}\end{array}$} & రా \\
\hline 0 & 148 & & & 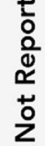 \\
\hline \multirow{2}{*}{$\begin{array}{l}\text { Observational or } \\
\text { Interventional Study }\end{array}$} & Interventional & 1 & 20 & 1 \\
\hline & Observational & 34 & 116 & 0 \\
\hline \multirow[t]{2}{*}{ Interventional } & Interventional Study & 0 & 7 & 1 \\
\hline & Randomized Controlled Trial & 1 & 13 & 0 \\
\hline \multirow{3}{*}{$\begin{array}{l}\text { Type of } \\
\text { Observational Study }\end{array}$} & Cohort & 5 & 1 & 0 \\
\hline & Cross-Sectional Survey & 26 & 97 & 0 \\
\hline & Mixed-Methods & 3 & 18 & 0 \\
\hline \multirow[t]{12}{*}{ Sampling Method } & Probability Sampling Method & 5 & 78 & 0 \\
\hline & Cluster Sampling & 1 & 32 & 0 \\
\hline & Random Sampling (Simple, Stratified, Systematic) & 3 & 45 & 0 \\
\hline & Other Probability Sampling Method & 1 & 1 & 0 \\
\hline & Non-Probability Sampling Method & 26 & 37 & 0 \\
\hline & Convenience Sampling & 20 & 10 & 0 \\
\hline & Purposive Sampling & 4 & 20 & 0 \\
\hline & Quota Sampling (Proportional) & 0 & 2 & 0 \\
\hline & Other Non-Probability Sampling Method & 2 & 5 & 0 \\
\hline & Mixed (Probability \& Non-Probability) Sampling & 1 & 3 & 0 \\
\hline & Probability \& Non-Probability Methods & 1 & 2 & 0 \\
\hline & Not Reported & 3 & 18 & 1 \\
\hline \multirow{5}{*}{$\begin{array}{l}\text { Measurement } \\
\text { Method }\end{array}$} & Administrative/Health Data & 3 & 0 & 0 \\
\hline & Audio Computer-Assisted Self-Interview & 1 & 8 & 0 \\
\hline & Interviewer-Administered Questionnaire & 27 & 120 & 1 \\
\hline & Self-Administered Questionnaire & 4 & 4 & 0 \\
\hline & Not Reported & 0 & 4 & 0 \\
\hline
\end{tabular}

Fig. 5 Distribution of the data collection methods

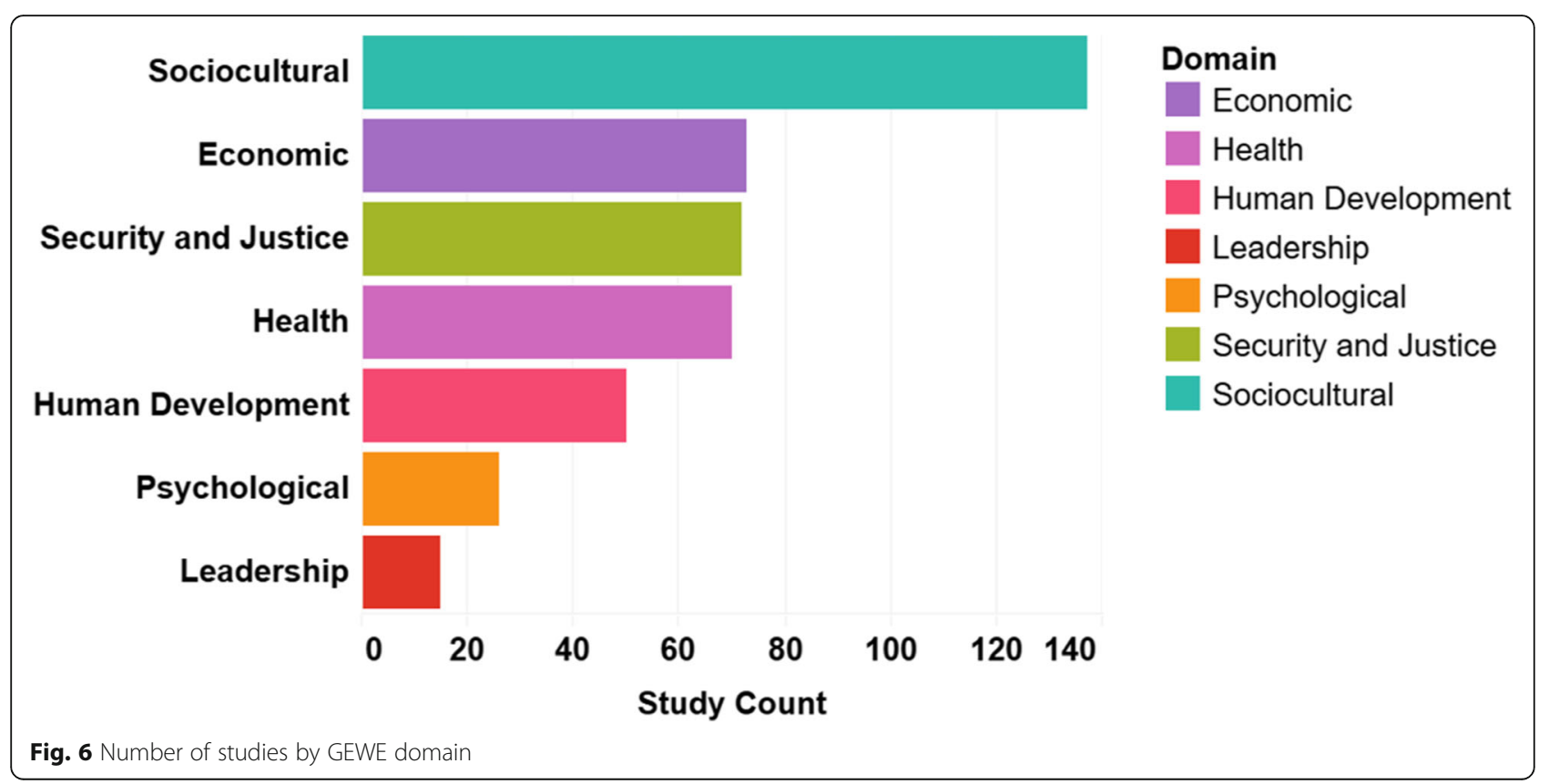




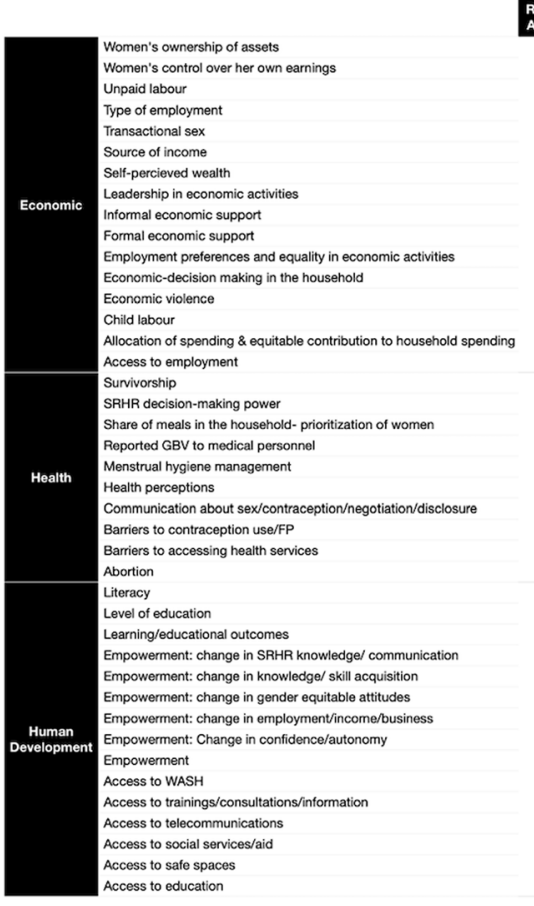

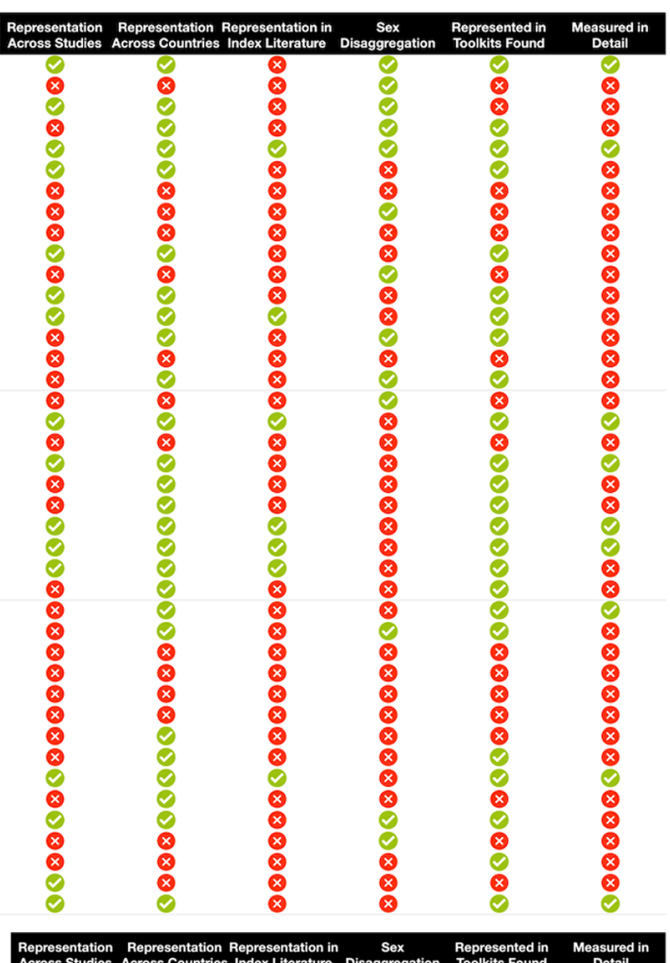

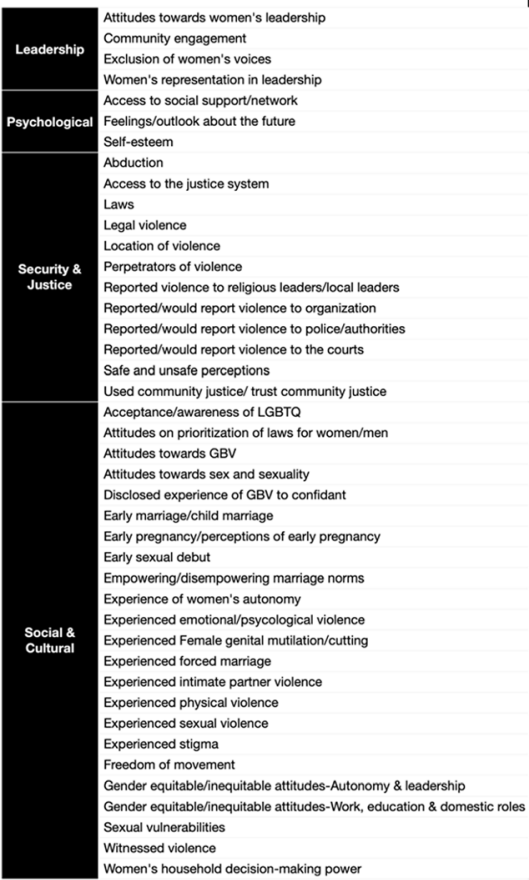

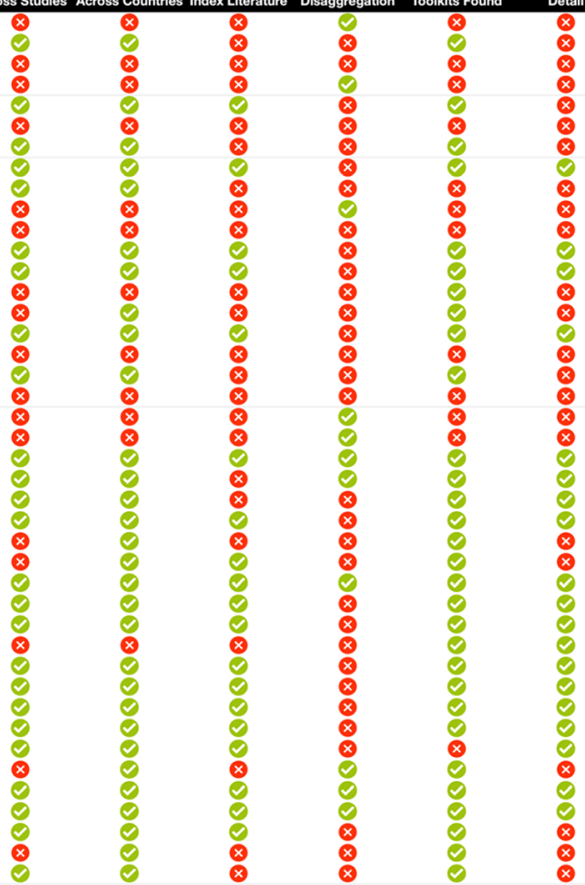

Fig. 7 Measurement gap areas

in humanitarian settings, measures of women's agency in the economic domain were limited. Indicators measuring women's allocation of spending were only found in $1 \%$ of the studies $(n=2)$, were often not sex-disaggregated, and were not included in toolkit measures. Similarly, indicators about women's economic decision-making were not commonly measured $(n=2,1 \%)$.

Women's economic decision-making in a leadership and enterprise context $(\mathrm{n}=2,1 \%)$ also lacked coverage in the peer-reviewed literature $(n=0)$ and was only measured in the disaster context. Although measurement of 
the women's income indicator type was common in humanitarian settings $(n=19,11 \%)$, women's control over their own earnings was not routinely measured $(n=3$, $2 \%)$. The employment indicator type as a whole was found in 18 studies (11\%), only $27 \%$ of which were peerreviewed studies. Additionally, measures of informal economic support (IES) were limited in humanitarian contexts and were only captured by two (1\%) publications from the non-peer-reviewed literature. Unpaid labor (including men and women's domestic responsibilities) were found in 18 studies (11\%), only 3 of which were peer-reviewed studies.

Transactional sex appeared in 23 publications (14\%), including 19 papers in the peer-reviewed literature. Economic violence was measured in 12 studies (7\%) across ten countries. Women's ownership of assets was found in 11 studies $(6 \%)$, three of which were peer-reviewed studies.

\section{Health}

Health data lacked sex-disaggregation. SRHR decisionmaking power $(n=20,12 \%)$, barriers to contraception/ FP $(n=19,11 \%)$ and barriers to accessing health services $(n=17,10 \%)$ were less commonly identified. Some topics, including menstrual hygiene management (MHM) $(n=6,3.5 \%)$, and abortion $(n=6,4 \%)$ were identified much less frequently in this review. A lack of coverage and infrequent use of indicators and data on the share of meals within the household (women's prioritization) was also evident $(n=3,2 \%)$. Survivorship by gender was only measured in 1 study $(0.6 \%)$. The majority of health indicators were found in the peerreviewed literature.

\section{Human development}

Learning/educational outcomes were not captured by our review, with the exception of literacy, which was found in 5 studies (3\%). Access to telecommunications appeared infrequently in our scoping review $(n=1,0.6 \%)$.

Access to trainings/consultations was found in 17 studies (10\%), 5 (3\%) of which were peer-reviewed publications. Access to basic needs/essential infrastructure was present in $17(10 \%)$ studies, only three $(2 \%)$ of which were peer-reviewed literature. Indicators that measure empowerment as an outcome (change/effect) from an intervention appeared in only 6 studies, 2 of which were peer-reviewed. Even when pooling all the empowerment subtypes, it appeared only in $10 \%$ of the studies $(n=17)$.

\section{Leadership}

There was a clear gap in leadership studies in our review, as only 15 studies (9\%) mentioned this domain. The majority of the leadership indicators were related to community engagement $(n=14,8 \%)$, with only six studies (4\%) including indicators about women's leadership, none of which were peer-reviewed publications.

\section{Psychological}

The psychological domain was identified in 26 studies included in this review (15\%). While there were some studies with psychological indicators related to social networks $(n=19,11 \%)$, fewer studies $(n=10,6 \%)$ had indicators related to self-esteem. More specifically, the indicator subtype feelings/outlook about the future was only found in two studies. All of these types/subtypes were uncommon in the peer-reviewed literature.

\section{Security and justice}

Some aspects of security and justice were identified in multiple studies and include abduction $(n=20,12 \%)$, locations of violence $(n=14,8 \%)$ and perpetrator information $(n=49,29 \%)$. However, systems-related topics, including those pertaining to laws that protect women $(n=3,2 \%)$, legal violence ( $n=1,0.6 \%)$, and access to the justice system $(n=13,8 \%)$ were infrequently measured, were found predominately in the non-peer-reviewed literature. Since measuring legal violence predicates on measuring access to the legal system, it is logical that the coverage of this indicator is accordingly low.

\section{Sociocultural}

The sociocultural domain was the largest domain in this review $(n=137,81 \%)$. GBV was the most frequent indicator in this domain and in the review overall $(n=113$, $66 \%$ ). GBV sub-types such as sexual violence, physical violence, and intimate partner violence (IPV) were measured in 65 (38\%), 41 (24\%) and $45(26 \%)$ studies respectively. GBV attitudes were present in 33 (19\%) studies.

Our review captured important measures of GEWE such as women's autonomy $(n=29,17 \%)$ and gender equitable attitudes $(n=25,15 \%)$. Indicator types related to marriage, such as age of first marriage (including child marriage), forced marriage and marriage norms were found in 25, 16, and 19 studies $(15,10,11 \%)$ respectively. Indicators for acceptance of individuals who identify as lesbian, gay, bisexual, transgender and/or queer $(L G B T Q+)(n=2,1 \%)$ and awareness of individuals who identify as $L G B T Q+$ community members ( $n=$ $1,0.6 \%$ ) were not often measured or included in the toolkits assessed.

Despite the substantial number of studies using indicators pertaining to the sociocultural domain, there were several gaps in indicator types within this domain. Early pregnancy $(n=6,4 \%)$, female genital mutilation/cutting $(\mathrm{FGM} / \mathrm{C})$ and other traditional practices $(n=11,6 \%)$, and rights and awareness of LGBTQ+ $(n=4,2 \%)$ were lacking in measurement. 
Though indicators of early pregnancy were included in toolkits, they were not commonly captured in our review, and appeared only in the non-peer-reviewed literature $(n=6,4 \%)$. Early pregnancy is defined as a pregnancy in an adolescent girl aged 19 or younger [23]. Adolescent girls constitute $22 \%(n=38)$ of the study populations included in this review (see study characteristics), making this a notable gap in measurement in the sociocultural domain. Only one publication reported the indicator proportion of girls who reported they had ever been pregnant [24]. Further, perceptions of early pregnancy were only measured in one non peer-reviewed literature study [25].

\section{Discussion}

\section{Discussion of measurement methods used}

Few interventional studies were identified in this review even though these are particularly important for capturing the effect of interventions that focus on empowerment, as a measure of changes in the degree of autonomy and/or self-determination in women through various interventions or programs. In addition, the lack of a control group for participants unexposed to an intervention or humanitarian event limits the interpretation of program/intervention effects [26, 27].

The majority of the studies in this review were crosssectional surveys. A random sample is a subset of the population in which each member has an equal probability of being chosen. Random sampling is meant to be unbiased, as it is an approximate to what would be obtained if the entire population was sampled [28]. Random sampling is the best method to use for crosssectional surveys, as it allows the results to be generalizable to the population [29]. In the context of health in humanitarian settings, it allows for a more accurate measure of the indicator across the population. However, probability sampling may not be feasible in every humanitarian setting. Violence, displacement, and insecurity can make sampling difficult [30]. Additionally, poor infrastructure can limit research capacity, compromising the validity of the research findings [30]. These challenges may result in the use of nonprobability sampling methods [31]. In our review, studies used non-probability sampling, limiting their ability to make causal claims and to generalize their findings to the broader population [32-35]. For example, studies that only recruit women seeking care in primary health settings may lead to selection bias [36-38].

Interviewer-administered and self-administered questionnaires can be subject to social desirability bias, as participants may be reluctant to disclose personal information, or may want to appeal to the perceived views and opinions of the interviewer [25, 32, 39-41]. Retrospective questionnaires are also prone to recall bias [42].

\section{Economic}

Economic initiatives are often touted as a means to women's empowerment. Multiple developmental programs and research initiatives have focused on women's economic empowerment in humanitarian settings [4345]. The lack of measurement of women's control of their own earnings is a significant gap in the measurement of economic empowerment, as it represents the lack of women's agency [8].

Additionally, measures of women's economic decisionmaking may be lacking because conflict-settings provided minimal opportunities for women's leadership overall, thereby limiting opportunities for women's economic leadership. Overall, women's involvement in economic decision-making was captured by indicators found in this review. However, the degree of involvement varied; shared economic decision-making often did not mean equal decision-making capacity for men and women. Therefore, future measurements of women's economic decision-making and women's allocation of spending must capture this nuance.

Economic support can be through formal or informal means. Formal economic support (FES) refers to the formal financial institutions that offer structured loans with quality assurance mechanisms in place, which often have high economic and opportunity costs for those in LMICs. Informal economic support (IES) includes friends, family, and rotating savings schemes, which are more accessible by those living in humanitarian settings [46]. For the purposes of this review, economic interventions/development programs are grouped with FES. Only $5 \%$ of borrowers in countries with humanitarian crises borrowed from a formal financial institution [46]. Therefore, measurement of IES should not be limited to the non-peer-reviewed literature as it serves as a useful resource for women in crisis-settings when FESs are limited. Loss of income and poverty may contribute to the prevalence of transactional sex [47, 48]. Transactional sex is considered a risky sexual behavior [49] and may also be associated with experiences of sexual violence, which would explain its prevalence within our included studies.

\section{Health}

The health in the gender equality and women's empowerment literature lacks sex-disaggregated data as many of the indicators are female-specific. The lack of sex-disaggregation in the health domain is not necessarily an issue, as indicators related to abortion, pregnancy, birth and menstruation predominately impact those who identify as women, and do not apply to most men. Health-related indicators are the focus of the SRHR scoping review published elsewhere [12]. Inequalities in household meal-allocation between men and women in 
humanitarian settings, are not well understood due a gap in measurement of this indicator. This is a concern, as adult women, even those who are pregnant, may be given last priority for meals in times of scarcity.

\section{Human development}

Human development was more often identified in nonpeer-reviewed literature reports than in the peerreviewed literature. Indicators of educational/learning outcomes were not frequently identified in this review. Educational interventions in humanitarian settings may not be evaluated using traditional outcomes such as literacy and numeracy; evaluating gender-disaggregated attendance or participation may be prioritized over academic achievement alone [50, 51]. Further, in humanitarian settings, education might not be delivered in a traditional format nor focused on traditional topics with well-established measurement standards, including numeracy and literacy rates [51]. In humanitarian settings, schooling may be replaced by training, or programming that focuses on SRH knowledge [39] or business/vocational skills $[43,52]$. Indicators related to education in humanitarian settings include those by the Inter-agency Network for Education in Emergencies [51]. These indicators were not retrieved in our review.

The lack of sex-disaggregation related to education, empowerment and access to services represents a gap in the literature. Sex-disaggregation is important when evaluating indicators of gender equality and empowerment, especially those related to access to education and services. In order to fully understand what is needed to promote equality and empowerment, an indicator must show how women fare compared to men or to the general population. The identification of existing inequalities through sex-disaggregation helps ensure that future policies and interventions are gender responsive [7].

Telecommunication access is a SDG sex-disaggregated indicator [1]. Empowerment interventions in conflictsettings that focus on the utility of mobile technology, such as in delivering early warning systems, and alerting users to the availability of aid, may help to bridge this gap [53]. A case study from two refugee contexts in East Africa [54] found that women were less likely than men to use a mobile phone or mobile internet, and disproportionately relied on borrowing phones from others. The study also found that women lacked the digital and literacy skills necessary to work various features of mobile phones [54].

In our scoping review, indicators of empowerment as a measure of change/effect resulting from an intervention, are classified as empowerment indicators. These were defined as a quantitative difference in attitudes, knowledge, or income, post-intervention and were rarely reported in the reviewed studies. Agency, which is a different conceptualization of empowerment that is not a consequence of an intervention, but rather a trait that defines the individual as an agent of change for their own development, and the development of the community around them [13] is classified in our scoping review under the psychological and leadership domains, respectively.

\section{Leadership}

Leadership was the domain with the lowest number of identified indicators. This lack of leadership measurement could in part be due to the scope of this review, as it did not capture national-level data. For example, the SDG indicator, proportion of seats held by women in national parliaments and local governments, was not captured for this reason. Nevertheless, there is a gap in the measurement of community-level leadership in conflict and disaster settings.

Leadership interventions may not be prioritized in humanitarian settings, especially in the immediate aftermath of a humanitarian event, where the health and security needs are prioritized. With the assistance of leadership interventions, women's leadership can grow in refugee communities [55]. Women and girls can contribute to crisis responses, strengthening social cohesion and preventing conflict between displaced and host communities. Women should be engaged as leaders and policymakers in risk reduction, to help ensure that gender specific needs are met in these settings. Women are also disproportionately impacted by natural disasters and play an important role in community-level resilience [55]. The lived experiences of women are crucial to governance in humanitarian settings, thus indicators of women's involvement in this kind of leadership are necessary. It is also important to measure both men and women's attitudes towards women's leadership [56].

\section{Psychological}

As mentioned above, indicators within the psychological domain were uncommon in this review. Self-esteem is a measure of women's empowerment, and has been included in women's empowerment frameworks around the world [57]. Improved self-esteem can increase selfefficacy, self-worth and sense of belonging in a community $[57,58]$. Therefore, indicators measuring psychological well-being should be better captured in humanitarian settings.

\section{Security and justice}

Locations of violence and perpetrators of violence appeared across multiple studies, countries and in the peer-reviewed literature, due to the high prevalence of gender-based violence measures. 
Access to the justice system, laws and perception of safety were not common in the peer-reviewed literature. This may indicate that qualitative methods have been used to collect information on these topics, or it might reflect the perception that legal governance/the justice system is too far removed from the experiences of women in humanitarian settings. However, for holistic change, it may be necessary to advocate for these robust systems of justice to ensure that women's rights are being protected [59] and measuring these indicators might bridge this gap.

\section{Sociocultural}

The predominance of GBV indicators in this review may be a reflection of the prevalence of violence in crisisaffected settings. Violence against women and girls (VAWG) can be used as a weapon of war, and a lack of security in camps and informal settlements can allow for an increased perpetration of violence [33, 60-67]. Stress caused by disaster, political instability and loss of income can increase relationship tensions, leading to increased IPV [68-71]. However, this concept is based on the psychobiology of stress theory of IPV, and is not the sole explanation for IPV [72]. Different theories exist to attempt to explain IPV, and there is intersectionality between these theories [73]. The depth of GBV research in both the peer-reviewed and non-peer-reviewed literature illustrate that the severity of GBV in humanitarian settings is recognized by non-governmental organizations (NGOs) and governments.

The prevalence of early/child marriage captured in this review may be explained by the economic and physical insecurity caused by conflict and displacement. Parents may believe it can alleviate the economic burden of providing food or clothing to their female children. Child marriage may also be a misguided attempted to "protect" girls from sexual violence in informal settlements [74].

Women's autonomy and gender equitable attitudes were measured throughout this review. It is important to measure changes in gender roles at the household and community level after the onset of a humanitarian event, as women become increasingly more vulnerable to violence, lack of access to essential services, loss of income and an increase in domestic/family responsibilities $[53,75,76]$. It is also to measure men's attitudes alongside women's, which was why the gender equitable men's scale was used in multiple studies. It measures attitudes towards gender roles within the home [48, 56, 75-77].

Not all indicator types within the sociocultural domain were commonly identified. One example is early pregnancy, which impacts girls' school enrolment and attendance [24], thereby curtailing their access to education and opportunities for employment. Therefore, future empowerment projects among adolescent girls in conflict-affected settings would benefit from the use of agreed-upon measures of early pregnancy.

As highlighted in our results, FGM/C was not commonly identified in this review. The elimination of all harmful practices, including FGM/C, is a target outlined by SDG five [1]. Programs and/or interventions for FGM/C and other harmful practices, and VAWG are often executed independently from one another [78]. However, these programs and/or interventions may benefit from coordinated implementation and evaluation [78]. To fully understand violence against women and girls, it is necessary to consistently collect data on comparable indicators of FGM/C specifically, so that it is not masked by more general violence indicators [78]. It is also important to measure the prevalence and attitudes towards $\mathrm{FGM} / \mathrm{C}$ to address these harmful practices and achieve gender equality across the various domains of women's lives [1]. Methodologies used to capture VAWG may also be used to develop and implement FGM/C evaluations [78] so that more detailed, standardized, and global evidence of this practice is available.

Notably, LGBTQ+ acceptance and awareness constitute a significant gap in this review. This may be because homosexuality is criminalized in some of these settings, and/or speaking about LGBTQ+ issues is taboo in the cultural context [56, 77]. Future measurement initiatives require culturally sensitive approaches to capture the LGBTQ+ experience in conflict/humanitarian settings.

\section{Limitations}

Indicators were only extracted if they reported quantitative outcomes, thereby excluding toolkits and checklists that were retrieved directly in our non-peer-reviewed literature search and were not used in any of the included publications. We excluded qualitative studies; therefore, it is possible that a number of in-depth studies related to equality and empowerment were excluded. Second, only studies written or translated into the English language were included due to our limited capacity to translate, thus excluding papers written in local languages. Third, this study did not include nationwide data, rendering our results less comparable to existing national indicators of empowerment and equality. We could not compare our indicators to the majority of the indicators that fall under SGD five, including the proportion of parliamentary seats held by women. Fourth, this review was heteronormative, as the majority of studies equated the term women to biological female sex, and not gender identity. There was little to no inclusion of transgender and non-binary people. Fifth, we only captured the interventions that have been evaluated and documented, not the entirety of what is being implemented for GEWE in conflict and other humanitarian settings. The lack of peer-reviewed publications on certain domains of 
equality and empowerment may reflect the challenges faced by NGOs working in humanitarian crises to publish in peer-reviewed journals and not a dearth of data. Thus, there may be fewer interventional studies in humanitarian settings, but not necessarily a lack of available interventions. Sixth, standardized age classification would have been preferable, as it increases the comparability of indicators across settings. We had to create our own age classifications, and many studies fell into multiple categories. Seventh, the distinctions between our subtypes were often subtle, and in some cases contentious, as some indicators like empowerment fall into multiple domains. Finally, for this review, unlike in our SRHR review, we did not compare our findings with a specific framework or standard indicators. There are less validated indicators and methodologies for measuring GEWE as compared to SRHR, rendering comparison challenging.

\section{Conclusions}

While there has been some effort to measure GEWE in humanitarian settings, there are significant gaps. A range of sampling methods were used in this review, yet the vast majority of studies employed an observational design. The lack of interventional studies found in this review demonstrated that humanitarian organizations should prioritize publishing literature on women's empowerment interventions, whilst using reliable measurement methods. The interactive Tableau dashboard illustrates the gaps, methods and indicators found in this review, and can be updated based on future GEWE research.

Violence and security indicators were commonly identified in this review, while human development, leadership and economic empowerment indicators were lacking. Some of these gaps can be attributed to the lack of a comprehensive framework for measuring GEWE in humanitarian settings. Though challenging to develop, this measurement framework could streamline data collection, and increase the comparability of indicators across diverse settings. With the onset of the COVID-19 pandemic, women and girls are becoming increasingly vulnerable to gendered impacts of conflicts, disasters, and epidemics. Therefore, it becomes even more imperative to have reliable, validated tools and indicators to measure GEWE in humanitarian settings.

\section{Abbreviations}

ACASI: Audio Computer-Assisted Self-Interviews; ALNAP: Active Learning Network for Accountability and Performance; CanWaCH: Canadian Partnership for Women and Children's Health; CARE: Care International; DHS: Demographic and Health Survey; FES: Formal Economic Support (FES); FGM/C: Female Genital Mutilation/Cutting; FP: Family Planning; GBV: GenderBased Violence; GEWE: Gender Equality and Women's Empowerment; IAWG: Inter-Agency Working Group on Reproductive Health in Crises; ICRC: International Committee of the Red Cross; ICRW: International Center for Research on Women; IDP: Internally Displaced Persons; IES: Informal Economic Support (IES); IPV: Intimate Partner Violence; IRC: International Rescue Committee; LGBTQ+: Lesbian, gay, bisexual, transgender and queer or questioning; LMICs: Low- and Middle- Income Countries; MHM: Menstrual Hygiene Management; MSF: Médecins Sans Frontières; NGOs: NonGovernmental Organizations; PRISMA: Preferred Reporting Items for Systematic Reviews; SCI: Save the Children International; SDGs: Sustainable Development Goals; SRHR: Sexual and Reproductive Health and Rights; SVRI: Sexual Violence Research Initiatives; UNDP: United Nations Development Programme; UNFPA: United Nations Population Fund; UNHCR: United Nations High Commission for Refugees; VAWG: Violence Against Women and Girls; WHO: World Health Organization; WRA: Women of Reproductive Age

\section{Supplementary Information}

The online version contains supplementary material available at https://doi. org/10.1186/s13031-021-00373-6.

Additional file 1. Search strategy. This file includes the search strategy for all 6 databases.

Additional file 2. Inclusion and exclusion criteria. This file includes the inclusion and exclusion criteria for the review.

Additional file 3. Machine learning tool. This file explains the machine learning tool we used to conduct the title/abstract screening phase of the review.

Additional file 4. Data collection toolkits and surveys. This file explains the data collection tools used by studies included in this review.

Additional file 5. Measurement of Sexual and Reproductive Health and Rights, Gender Equality, and Women's Empowerment in Humanitarian Settings. This link leads to the interactive Tableau dashboard. https:// public.tableau.com/profile/humairanakhuda\#!/vizhome/

SRHRGEWEScopingReviewStory_Final_Nov16/SRHRGEWEStory.

Additional file 6. Included studies. This file contains all of the included studies retrieved in both the peer-reviewed and non-peer-reviewed literature searches.

Additional file 7. Studies by disaster type. This file contains a list of all publications by disaster type.

Additional file 8. Indicator types and subtypes. This file contains the calculated frequency of each indicator type and subtype organized by domain.

\section{Acknowledgements}

Canadian Partnership for Women and Children's Health (CanWaCH), Canadian Red Cross, Luay Basil, Katie McLaughlin, Mariella Munyuzangabo, Neil Yang \& Malasha D'souza.

\section{Authors' contributions}

CG coordinated the study, analyzed the data, planned, wrote and edited the manuscript and directed the team. She also participated in screening, data extraction and cleaning of the study. AP, AG and AA screened, extracted and cleaned the data. They also contributed to manuscript writing and editing. $\mathrm{HN}$ created all the Tableau visuals, and is responsible for the development of the online Interactive Tableau platform. She also edited and contributed to the writing process. JLK ran the machine learning aspect of the project, and wrote the corresponding file (Additional file 3). DB is the principal investigator and was responsible for the creation of this project in partnership with $\mathrm{CanWaCH}$. The authors read and approved the final manuscript.

\section{Funding}

Funded by Global Affairs Canada and the Canadian Partnership for Women and Children's Health.

\section{Availability of data and materials}

The datasets generated during and/or analyzed during the current study are available from the corresponding author on reasonable request. 


\section{Declarations}

\section{Ethics approval and consent to participate} N/A

\section{Consent for publication}

N/A

\section{Competing interests}

There are no competing interests to report.

\section{Received: 29 December 2020 Accepted: 27 April 2021} Published online: 17 May 2021

\section{Refer}

1. Transforming our world: the 2030 Agenda for Sustainable Development Sustainable Development Knowledge Platform [Internet]. United Nations; 2015. [cited 2020 Aug 24]. Available from: https://sustainabledevelopment. un.org/post2015/transformingourworld/publication.

2. UNHCR. Refugee Data Finder 2020 [Available from: https://www.unhcr.org/ refugee-statistics/.

3. Aolain FN. Women, vulnerability, and humanitarian emergencies. Mich Gender \& L. 2011;18(1):1-23.

4. World Health Organization. Gender and health in disasters. Geneva: World Health Organization; 2002.

5. UN Women. Closing the Gender Gap in Humanitarian Action [Available from: https://interactive.unwomen.org/multimedia/infographic/humanitaria naction/en/index.html.

6. United Nations Children's Fund. Gender equality in humanitarian action. New York: UNICEF; 2012

7. Dazé A, Church C. Toolkit for a gender-responsive process to formulate and implement National Adaptation Plans (NAPs). Winnipeg: NAP Global Network \& UNFCCC; 2019

8. Kabeer N. Resources, agency, achievements: reflections on the measurement of Women's empowerment. Dev Chang. 1999:30(3):435-64. https://doi.org/10.1111/1467-7660.00125.

9. Pratley P. Associations between quantitative measures of women's empowerment and access to care and health status for mothers and their children: a systematic review of evidence from the developing world. Soc Sci Med. 2016;169:119-31. https://doi.org/10.1016/j.socscimed.2016.08.001.

10. James-Hawkins L, Peters C, VanderEnde K, Bardin L, Yount KM. Women's agency and its relationship to current contraceptive use in lower- and middle-income countries: a systematic review of the literature. Glob Public Health. 2018;13(7):843-58. https://doi.org/10.1080/17441692.2016.1239270.

11. Doku DT, Bhutta ZA, Neupane S. Associations of women's empowerment with neonatal, infant and under-5 mortality in low- and /middle-income countries: meta-analysis of individual participant data from 59 countries. BMJ Glob Health. 2020;5(1):e001558. https://doi.org/10.1136/bmjgh-2019001558

12. Goulart C, Giancola A, Nakhuda H, Ampadu A, Purewal A, Kortenaar J-L, et al. Tools for measuring sexual and reproductive health and rights (SRHR) indicators in humanitarian settings. 2020. https://www.medrxiv.org/ content/10.1101/2021.03.23.21254101v1.

13. van Eerdewijk A, Wong F, Vaast C, Newton J, Tyszler M, Pennington A. White paper: A conceptual model on women and girls' empowerment. Amsterdam: Royal Tropical Institute (KIT); 2017.

14. Martineau T, McPake B, Theobald S, Raven J, Ensor T, Fustukian S, et al. Leaving no one behind: lessons on rebuilding health systems in conflictand crisis-affected states. BMJ Glob Health. 2017;2(2):e000327. https://doi. org/10.1136/bmjgh-2017-000327

15. Peterson J, Pearce PF, Ferguson LA, Langford CA. Understanding scoping reviews: definition, purpose, and process. J Am Assoc Nurse Pract. 2017 29(1):12-6. https://doi.org/10.1002/2327-6924.12380.

16. Arksey H, O'Malley L. Scoping studies: towards a methodological framework Int J Soc Res Methodol. 2005;8(1):19-32. https://doi.org/10.1080/1364557032 000119616.

17. Tricco AC, Lillie E, Zarin W, O'Brien KK, Colquhoun H, Levac D, et al. PRISMA extension for scoping reviews (PRISMA-SCR): checklist and explanation. Ann Intern Med. 2018;169(7):467-73. https://doi.org/10.7326/M18-0850.
18. Blanchet K. An evidence review of research on health interventions in humanitarian crises. London: London School of Hygience and Tropical Medicine; 2015

19. Howard J, Gugger S. Fastai: a layered API for deep learning. Information. 2020;11(2):108. https://doi.org/10.3390/info11020108.

20. Popay J, Roberts H, Sowden A, Petticrew M, Arai L, Rodgers M, et al. Guidance on the conduct of narrative synthesis in systematic reviews: a product from the ESRC methods Programme: ESRC; 2006. https://doi.org/1 $0.13140 / 2.1 .1018 .4643$

21. Mehmetoglu M, Jakobsen TG. Applied statistics using Stata: a guide for the social sciences: SAGE publications; 2016.

22. Nakhuda H. Measurement of sexual and reproductive health and rights, gender equality, and women's empowerment in humanitarian settings: the hospital for sick children; 2020 [Available from: https://public.tableau.com/ profile/humairanakhuda\#!/vizhome/SRHRGEWEScopingReviewStory_Final Nov16/SRHRGEWEStory.

23. World Health Organization. Adolescent Pregnancy 2020 [Available from: https://www.who.int/news-room/fact-sheets/detail/adolescent-pregnancy.

24. Plan International, Monash University's Gender PaSRC. Adolescent girls in crisis: experiences of risk and resilience across three humanitarian settings. Surrey: Plan International; 2018.

25. Tanner S, O'Connor M. A safe place to shine: creating opportunities and raising voices of adolescent girls in humanitarian settings. New York: International Rescue Committee; 2017.

26. Mcllvaine K, Oser C, Lindsey J, Blume M. Confidence, capacity building and cash: achieving sustained impact for ultra-poor Women. IDS Bull. 2015;46(2): 83-92. https://doi.org/10.1111/1759-5436.12131.

27. Usta J, Farver J. Child sexual abuse in Lebanon during war and peace. Child Care Health Dev. 2010;36(3):361-8.

28. Shadish WR, Cook TD, Campbell D. Experimental and quasi-experimental designs for generalized causal inference. Boston: Houghton Mifflin Company; 2002

29. Alexander J, Cosgrave J. Representative sampling in humanitarian evaluation, method note 1. ALNAP Humanitarian Evaluation Community of Practice; 2014

30. Ford N, Mills EJ, Zachariah R, Upshur R. Ethics of conducting research in conflict settings. Confl Heal. 2009;3(1):7. https://doi.org/10.1186/1752-1505-3-

31. Klasen F, Oettingen G, Daniels J, Adam H. Multiple trauma and mental health in former Ugandan child soldiers. J Trauma Stress. 2010;23(5):573-81. https://doi.org/10.1002/jts.20557.

32. Ivanova O, Rai M, Mlahagwa W, Tumuhairwe J, Bakuli A, Nyakato VN, et al. A cross-sectional mixed-methods study of sexual and reproductive health knowledge, experiences and access to services among refugee adolescent girls in the Nakivale refugee settlement. Uganda Reprod Health. 2019;16(1): 35. https://doi.org/10.1186/s12978-019-0698-5.

33. Albutt K, Kelly J, Kabanga J, VanRooyen M. Stigmatisation and rejection of survivors of sexual violence in eastern Democratic Republic of the Congo. Disasters. 2017:41(2):211-27. https://doi.org/10.1111/disa.12202.

34. Al-Shdayfat N. Physical abuse among Syrian refugee Women in Jordan. Middle East J Nurs. 2017:11(1):3-7. https://doi.org/10.5742/MEJN.2017.92930.

35. Khawaja M, Hammoury N. Coerced sexual intercourse within marriage: a clinic based study of pregnant Palestinian refugees in Lebanon. J Midwifery Womens Health. 2008;53(2):150-4. https://doi.org/10.1016/j.jmwh.2007.09.001.

36. de Jong K, van der Kam S, Swarthout T, Ford N, Mills C, Yun O, et al. Exposure to violence and PTSD symptoms among Somali women. J Trauma Stress. 2011;24(6):628-34. https://doi.org/10.1002/jts.20694.

37. Hammoury N, Khawaja M, Mahfoud Z, Afifi RA, Madi H. Domestic violence against women during pregnancy: the case of Palestinian refugees attending an antenatal clinic in Lebanon. J Women's Health (Larchmt). 2009; 18(3):337-45. https://doi.org/10.1089/jwh.2007.0740.

38. Goldenberg SM, Muzaaya G, Akello M, Braschel M, Birungi J, Shannon K. High burden of previously undiagnosed HIV infections and gaps in HIV care cascade for conflict-affected female sex workers in northern Uganda. Int J STD AIDS. 2019;30(3):275-83. https://doi.org/10.1177/0956462418804658.

39. Logie CH, Daniel C, Newman PA, Weaver J, Loutfy MR. A psychoeducational HIV/STI prevention intervention for internally displaced women in Leogane, Haiti: results from a non-randomized cohort pilot study. PLoS One. 2014;9(2):e89836. https://doi.org/10.1371/journal.pone.0089836.

40. Stark L, Seff I, Asghar K, Roth D, Bakamore T, MacRae M, et al. Building caregivers' emotional, parental and social support skills to prevent violence 
against adolescent girls: findings from a cluster randomised controlled trial in Democratic Republic of Congo. BMJ Glob Health. 2018;3(5):e000824. https://doi.org/10.1136/bmjgh-2018-000824.

41. Duff P, Birungi J, Dobrer S, Akello M, Muzaaya G, Shannon K. Social and structural factors increase inconsistent condom use by sex workers' onetime and regular clients in northern Uganda. AIDS Care. 2018;30(6):751-9. https://doi.org/10.1080/09540121.2017.1394966.

42. Falb KL, McCormick MC, Hemenway D, Anfinson K, Silverman JG. Violence against refugee women along the Thai-Burma border. Int J Gynaecol Obstet. 2013;120(3):279-83. https://doi.org/10.1016/j.ijgo.2012.10.015.

43. Jabbar SA, Zaza HI. Evaluating a vocational training programme for women refugees at the Zaatari camp in Jordan: women empowerment: a journey and not an output. Int J Adolesc Youth. 2015;21(3):304-19.

44. Wanyama JB. Diriswanaag Final Evaluation. Somalia: CARE International; 2013.

45. Managing Innovative Development Solutions - Consulting Services Inc. Mid-Term Evaluation: Typhoon Haiyan Reconstruction Assistance Project, CARE Philippines. CARE Philippines; 2017.

46. El-Zoghbi M, Chehade N, McConaghy P, Soursourian M. The role of Financial Services in Humanitarian Crises. Washington, D.C: CGAP, SPF, World Bank; 2017. https://doi.org/10.1596/26511.

47. Kinyanda E, Weiss HA, Mungherera M, Onyango-Mangen P, Ngabirano E, Kajungu R, et al. Psychiatric disorders and psychosocial correlates of high HIV risk sexual behaviour in war-affected eastern Uganda. AIDS Care. 2012; 24(11):1323-32. https://doi.org/10.1080/09540121.2011.647676.

48. Slegh H, Barker G, Levtov R. Gender relations, sexual and gender-based violence and the effects of conflict on Women and men in north Kivu, eastern Democratic Republic of the Congo: results from the international men and gender equality survey (IMAGES). Washington, DC and Capetown: Promundo-US, Sonke Gender Justice; 2014.

49. Okigbo CC, McCarraher DR, Chen M, Pack A. Risk factors for transactional sex among young females in post-conflict Liberia. Afr J Reprod Health. 2014;18(3):133-41.

50. Landis D, Yu G, Tanner S, Karungu C, Mallinga PA, Falb K, et al. The school participation effect: investigating violence and formal education among girls in the Democratic Republic of the Congo. Compare. 2018;49(5):817-36.

51. Anderson K, Read L, Losada E. Academic learning measurement and assessment tools in education in emergencies: identifying, analyzing, and mapping tools to global guidance documents. New York: Inter-agency Network for Education in Emergencies (INEE); 2020.

52. Green EP, Blattman C, Jamison J, Annan J. Women's entrepreneurship and intimate partner violence: a cluster randomized trial of microenterprise assistance and partner participation in post-conflict Uganda (SSM-D-1401580R1). Soc Sci Med. 2015;133:177-88. https://doi.org/10.1016/j. socscimed.2015.03.042

53. Gressmann W. From the ground up: gender and conflict analysis in Yemen. Oxford: Oxfam GB; 2016

54. Downer M. Bridging the mobile gender gap for refugees: a case study of women's use of mobile phones in Bidi Bidi refugee settlement and Kiziba refugee camp. Georgia: GSMA Mobile for Development; 2019.

55. Women UN. Enhancing women's leadership in humanitarian action, crisis response and disaster risk reduction: UN Women's approach. New York: UN Women; 2019

56. El Feki S, Barker G, Heilman B. Understanding masculinities: results from the international men and gender equality survey (IMAGES) - Middle East and North Africa: Egypt, Lebanon, Morocco, and Palestine. Cairo and Washington, D.C: Promundo-US, UN Women; 2017.

57. Huis MA, Hansen N, Otten S, Lensink R. A three-dimensional model of Women's empowerment: implications in the field of microfinance and future directions. Front Psychol. 2017;8:1678. https://doi.org/10.3389/fpsyg.2017.01678.

58. Okello F, Kabonesa C, Ojok F, Akot C, Nayebare H. Baseline evaluation of integrated emergency response program for south Sudanese refugees and affected host community members in rhino and Imvepi settlements, Arua District. Uganda: CARE International; 2018. https://sustainabledevelopment un.org/post2015/transformingourworld/publication.

59. United Nations Development Fund for Women. Pakistan floods 2010: rapid gender needs assessment of flood affected communities. Pakistan: UNIFEM; 2010.

60. Murphy M, Blackwell A, Ellsberg M, Contreras M. No safe place: a lifetime of violence for conflict-affected women and girls in South Sudan. UK: What Works to Prevent Violence Against Women and Girls in Conflict and Humanitarian Crises Consortium; 2017.
61. Hirschfeld K, Leaning J, Crosby S, Piwowarczyk L, VanRooyen J, Greenough $\mathrm{G}$, et al. Nowhere to turn: failure to protect, support and assure justice for Darfuri women. Massachusetts: Physicians for Human Rights, Harvard Humanitarian Initiative; 2009.

62. Hynes M, Robertson K, Ward J, Crouse C. A determination of the prevalence of gender-based violence among conflict-affected populations in East Timor. Disasters. 2004;28(3):294-321. https://doi.org/10.1111/j.0361-3666.2 004.00260.x.

63. Dossa NI, Zunzunegui MV, Hatem M, Fraser W. Fistula and other adverse reproductive health outcomes among women victims of conflict-related sexual violence: a population-based cross-sectional study. Birth. 2014;41(1): 5-13. https://doi.org/10.1111/birt.12085

64. Hossain M, Zimmerman C, Kiss L, Kone D, Bakayoko-Topolska M, Manan DK, et al. Men's and women's experiences of violence and traumatic events in rural cote d'Ivoire before, during and after a period of armed conflict. BMJ Open. 2014;4(2):e003644. https://doi.org/10.1136/bmjopen-2013-003644.

65. Kohli A, Perrin NA, Mpanano RM, Mullany LC, Murhula CM, Binkurhorhwa AK, et al. Risk for family rejection and associated mental health outcomes among conflict-affected adult women living in rural eastern Democratic Republic of the Congo. Health Care Women Int. 2014;35(7-9):789-807. https://doi.org/10.1080/07399332.2014.903953.

66. Kolbe AR, Hutson RA, Shannon H, Trzcinski E, Miles B, Levitz N, et al. Mortality, crime and access to basic needs before and after the Haiti earthquake: a random survey of Port-Au-Prince households. Med Confl Surviv. 2010;26(4):281-97. https://doi.org/10.1080/13623699.2010.535279.

67. Parmar P, Agrawal P, Greenough PG, Goyal R, Kayden S. Sexual violence among host and refugee population in Djohong District, Eastern Cameroon. Glob Public Health. 2012;7(9):974-94. https://doi.org/10.1080/17441692.2012. 688061

68. Avdibegovic E, Sinanovic O. Consequences of domestic violence on women's mental health in Bosnia and Herzegovina. Croat Med J. 2006;47(5): 730-41.

69. Saile R, Neuner F, Ertl V, Catani C. Prevalence and predictors of partner violence against women in the aftermath of war: a survey among couples in northern Uganda. Soc Sci Med. 2013;86:17-25. https://doi.org/10.1016/j. socscimed.2013.02.046

70. Shuman SJ, Falb KL, Cardoso LF, Cole H, Kpebo D, Gupta J. Perceptions and experiences of intimate partner violence in Abidjan, Cote d'Ivoire. PLoS One. 2016;11(6):e0157348. https://doi.org/10.1371/journal.pone.0157348.

71. Fulu E, Warner X, Miedema S, Jewkes R, Roselli T, Lang J. Why do some men use violence against Women and how can we prevent it? Quantitative findings from the United Nations multi-country study on men and violence in Asia and the Pacific. Bangkok: UNDP, UNFPA, UN Women, UNV; 2013.

72. Yim IS, Kofman YB. The psychobiology of stress and intimate partner violence. Psychoneuroendocrinology. 2019;105:9-24. https://doi.org/10.101 6/j.psyneuen.2018.08.017.

73. Kelly UA. Theories of intimate partner violence: from blaming the victim to acting against injustice: intersectionality as an analytic framework. ANS Adv Nurs Sci. 2011;34(3):E29-51. https://doi.org/10.1097/ANS.0b013e3182272388.

74. Women UN. Gender-based violence and child protection among Syrian refugees in Jordan, with a focus on early marriage. UN Women: Amman, Jordan; 2013.

75. Scott J, Hacker M, Averbach S, Modest AM, Cornish S, Spencer D, et al Influences of sex, age and education on attitudes towards gender inequitable norms and practices in South Sudan. Glob Public Health. 2014; 9(7):773-86. https://doi.org/10.1080/17441692.2014.928347.

76. International Rescue Committee. Gender based violence among displaced communities in sittwe township, rakhine state: a knowledge, attitudes and practices study: International Rescue Committee; 2016.

77. Mansour Z, Deeb M, Brandt L, Said R, Torossian L. Understanding masculinities results from the international men and gender equality survey (IMAGES) in Lebanon. UN Women; 2017.

78. Nelson G. Female genital mutilation/cutting and violence against women and girls: strengthening the policy linkages between different forms of violence. New York: UN Women; 2017.

\section{Publisher's Note}

Springer Nature remains neutral with regard to jurisdictional claims in published maps and institutional affiliations. 